\title{
Physiological Factors Relevant to Exercise Tests in Pulmonary Rehabilitation of COPD Patients
}

\author{
Esmaeil Alibakhshi' ${ }^{1,2}$, Luis Lores ${ }^{1}$ and Raffaele Fiorillo'. \\ ${ }^{1}$ Parc Sanitari Sant Joan de Deu, Health University of Barcelona Campus, Barcelona, Spain. \\ ${ }^{2}$ Exercise physiology research center, BMSU University of medical science, Tehran, Iran
}

\begin{abstract}
Chronic obstructive pulmonary disease (COPD) is a major cause of chronic morbidity and mortality in the world special in United States. Patients with COPD often complain of dyspnea and fatigue in exercise intolerance, also significantly impede quality of life of them. Main propose in this study is comparison all of Physiological Factors in reports and results of researches in relevance to Cardiopulmonary Rehabilitation in COPD patients with exercise approach. In this study with style of Theoretical basic research and data calculate of digital resources, PubMed, Science direct, Scopus, Guidelines of ERS/ATS with Bibliographic method. Our approach is comparison all of physiological factors in investigations relevant to exercise tests in cardiopulmonary rehabilitation of COPD patients include: $\mathrm{VO}_{2} \mathrm{Max}, \mathrm{VCO}_{2}$, VE, HR, FEV1, FVC, assessment of perceptual responses e.g. dysfunctions in muscle, dyspnea, leg discomfort, fatigue and such as exercise-related arterial oxygen desaturation, dynamic hyperinflation and limb-muscle strength. In many researches more improved of VO2max in Cardiovascular limitation than Ventilate limitation in COPD patients. In Cycle ergometer testing, COPD patients had less in elicit $\mathrm{O} 2$ desaturation that might occur in during lung ambulation. By using maximal incremental treadmill exercise test protocols can be developed and increased tolerance exercise in COPD patients. Treadmill testing have more physiological limitations than cycle ergometer and COPD patients often in treadmill tests have more limiting factors: dyspnea and coughing.
\end{abstract}

Keywords: COPD patients; Exercise tests; Cardio-pulmonary rehabilitation; Physiologic factors

\section{Introduction}

In this study we will explained about COPD patients and details about that and after that description about Exercise protocols and effects on lung function in this patients in daily activities and life style in COPD. So, we will explain kind of exercise protocols with details of that and changes of physiological factors of COPD duration of Cardiopulmonary Rehabilitation Exercise in these patients. Chronic obstructive pulmonary disease (COPD) is a major cause of chronic morbidity and mortality in the world special in United States. Currently COPD the fifth leading cause of death and disease on index burden globally; COPD is characterized by significant physical and psychosocial challenges. In these patients is characterized by chronic airflow limitation and a range of pathological changes in the lungs, some significant extra pulmonary effects, and importance comorbidities, which may contribute to the severity of the disease and Epidemic aspects in all of people. In these patients is clinically characterized by a pathological rate of decline in lung function with age, and, as a result, patients with COPD often complain of dyspnea and exercise intolerance, both of which not only interfere with the ability to perform the activities of daily life but also significantly impede quality of life. Main Propose in the study is comparison all of Physiological Factors in reports and results of researches and investigations in relevance to exercise tests in cardiopulmonary Rehabilitation of COPD patients and review effects and comparing of exercise rehabilitation protocols in improvement of symptoms and signs of COPD patients in during of cardiopulmonary rehabilitation in clinic and home exercise and comparing types of protocols in improvement of COPD patients [1-11].

\section{Severity and classification}

In this illnesses can be weakly reflected in the FEV1. A more comprehensive assessment in COPD patients by attention to severity and staging in them also include:

- Percentage of airflow obstruction and disability in these patients.

- Quantity of exacerbations and density.
- Prognostic factors such as breathlessness, coughing, carbon monoxide lung transfer factor (TLCO), health status, exercise capacity, BMI, $\mathrm{PaO}_{2}$.

According to studies on symptoms had been disproportion to the spirometry impairment using a CT scan or DLCO testing [11-15]. They told that one of best indexes for evaluation of COPD patients in all of situation is BODE index (BMI, airflow Obstruction, Dyspnoea and Exercise capacity index) should be used to assess the prognosis when the component information is available in this patients: measurement of the BODE index includes measurement of: BMI, FEV1 as a percentage for predicted, dyspnoea and exercise tolerance (6-MWD) when COPD patients have special condition of illnesses and evaluation of that (Table $1)$.

\section{Epidemiology}

In the other hand by attention to results reported of investigators and researchers COPD was originally a disease more commonly seen in men, but now the disease affects men and women almost equally, as observed in international data and on basic symptoms. Three million people are affected by COPD in the UK and about 900,000 have been diagnosed with COPD and an estimated two million people have COPD which remains undiagnosed in the world. The rate of COPD in the population is estimated at between $2 \%$ and $4 \%$ between all of people women or men. The diagnosed prevalence of COPD is $1.5 \%$ in population by attention to COPD illnesses and other respiratory

*Corresponding author: Esmaeil Alibakhshi, Parc Sanitari Sant Joan de Deu, Health University of Barcelona Campus, Barcelona, Spain, Tel: 0034603482230; E-mail: ealibaal7@alumnes.ub.edu

Received September 26, 2015; Accepted October 15, 2015; Published October 23, 2015

Citation: Alibakhshi E, Lores L, Fiorillo R (2015) Physiological Factors Relevant to Exercise Tests in Pulmonary Rehabilitation of COPD Patients. J Sports Med Doping Stud 6: 167. doi:10.4172/2161-0673.1000167

Copyright: (c) 2015 Alibakhshi $E$ et al. This is an open-access article distributed under the terms of the Creative Commons Attribution License, which permits unrestricted use, distribution, and reproduction in any medium, provided the original author and source are credited. 


$\begin{array}{lll}\begin{array}{l}\text { No } \\ 1\end{array} & \begin{array}{l}\text { Classification } \\ \text { At risk }\end{array} & \begin{array}{l}\text { severity of airflow obstruction as a percentage of predicted } \\ \text { Patients have chronic cough and sputum production. Spirometry in these patients is normal. }\end{array} \\ \mathbf{2} & \text { Mild } & \begin{array}{l}\text { Patients have mild airflow limitation FEV1/FVC with } 70 \% \text { and FEV1 } 80 \% \text { or more than predicted in spirometry; but in this patients not } \\ \text { always chronic cough and sputum production. }\end{array} \\ \text { Moderate } & \begin{array}{l}\text { Patients have worsening airflow limitation (FEV1 } 50-79 \%) \text { and in them usually progression of symptoms, with shortness of breath, } \\ \text { especially on exertion and decrease in O2 uptake in issues. }\end{array} \\ \text { Severe } & \begin{array}{l}\text { Patients have high worsening of airflow limitation (FEV1 } 30-50 \% \text { ), increased shortness of breath, and repeated exacerbations and } \\ \text { obstruction. }\end{array}\end{array}$

Table 1: Classification and severity of airflow obstruction as a percentage of predicted in chronic obstruction respiratory diseases. Reference: Ontario Health Technology Assessment Series, 2012.

illnesses. The prevalence increases with age, with an estimated prevalence of $10 \%$ increase in men older than women older. Most patients are not diagnosed until they are in their fifties special in UK and United states. COPD is closely associated with levels of deprivation rates of COPD are higher in more deprived communities than another respiratory illnesses. Women seem to be more sensitive to the negative effects of tobacco smoke, and develop very severe COPD to a larger extent compared to men in use of tobacco. Female COPD patients also demonstrate lower quality of life (QoL), more severe dyspnea and more sensitive airways than men with the same degree of airways obstruction and inflammation as per study. By attention these symptoms in women must be high health care in during of treatment female COPD patients in clinic and home programs. But we do not forget that Air pollution and industries can be more important for suffer from to COPD in all of countries and populations [15-25].

\section{Pathophysiology}

In the other hand COPD is a type of obstructive lung disease and is not fully identified how tobacco smoke and other intervention particles damage the lungs to cause COPD. The most important processes causing lung damage in these illnesses include:

-Productions of oxidative stress by the high concentrations of free radicals in tobacco when smoking and breathing tobacco.

-Productions of Cytokine released in airways due to inflammation as the body responds to irritant particles such as tobacco smoke.

-Both of Tobacco smoke and free radicals impair the activity of anti-protease enzymes such as alpha 1-antitrypsin, allowing protease enzymes to damage the lung without any antibody or defensive enzymes.

Decanter of the airways reduces the airflow rate to and from the alveoli and limits effectiveness of the lungs. In COPD, the greatest reduction in air flow occurs when breathing out (during expiration) and with high breathlessness because the pressure in the chest tends to compress rather than expand the airways. In theory, air flow could be increased by breathing more forcefully, increasing the pressure in the chest during expiration and more compress on cardiopulmonary system in these patients. In COPD, there is often a limit to how much this can actually increase air flow in airways and lung than ability breathing in any person and by attention to situation known as expiratory flow limitation in any COPD patients [25].

\section{Symptoms}

In these patients symptoms are debilitating lung condition that manifests in shortness of breath, activity limitation, increased sputum production, and cough, decrease exercise capacity, increased leg fatigue and dyspnea among the most frequently and peripheral muscle weakness and low total performance. In COPD patient's decreased capacity of local muscle endurance in both the upper and the lower limbs has been shown in COPD patients compared to healthy controls. In COPD patients in case of increased dyspnea during exercise in them whole body/large muscle mass exercises decreased cause many COPD patients to stop exercising before their cardiovascular system or skeletal muscles are maximally stressed in lung function. For remember that researchers doing studies have shown positive effects of single limb training (SLT) (that is, one-legged cycling/knee extensor training) in patients with COPD. Brønstad and colleagues explained by an increased capacity of local muscle endurance due to increased oxygen uptake, ventilation and increased maximal mitochondrial respiration in working muscles, as demonstrated in the one-legged knee extensor training study [20-30].

\section{Pulmonary hypertension}

In comparison to physiological changes in pulmonary function in COPD patients, the progression of other patient outcomes over time has been examined less frequently. One established complication of COPD is the development of pulmonary hypertension $(\mathrm{PH})$. Typically; in this result $\mathrm{PH}$ appears when airflow limitation is severe and is associated with chronic hypoxemia, the main pathophysiological cause being chronic alveolar hypoxia, although new mechanisms have emerged recently. In most cases, $\mathrm{PH}$ is mild to moderate but it may be severe and could be observed without major airflow limitation. Treatment of COPD has focused traditionally on pharmacological improvement of the airway obstruction. But in this treatment must be attention to hypertension in pulmonary system and airways synchronize airway obstruction.

\section{Exercise capacity, relative mortality and quality of life in COPD}

Really, exercise capacity is the strongest elements of disease and mortality and showed consistently and stable associations than lung function or dyspnea. For COPD patients the BODE index (body mass index, FEV1, dyspnea and 6-minute walk distance) includes exercise capacity to predict and characterize severity of illnesses and mortality. Also, indexes of outcomes such as exercise capacity help measurement the risk of future outcomes, the absolute effects of treatments for individuals and, thereby, the benefits and damages of treatments (e.g. number-needed-to-treat and health care). In the other hand, assessment of prognosis and diagnosis is of high importance and value not only for patients but also for policy makers and managers, orderly agents and clinical guideline developers in the many countries. Unfortunately, measurement and administrate of exercise capacity has not been implemented in most clinical practice settings relevant to COPD patients in many different of clinics of COPD rehabilitation. Exercise capacity and life style has probably rarely been tested and evaluated in the vast majority of COPD patients by attention that of its high importance in during of pulmonary rehabilitation program 
in COPD patients. Most the last ten years, in area of measurement and qualification of improvement COPD in process of pulmonary rehabilitation program a significant amount of research has been done to explore simpler and muscle special tests such as sit-to-stand (STS) or step by step tests to measure exercise capacity and tolerance or in another points the handgrip strength test to measure upper limb strength are many employment in clinic for COPD patients and other respiratory illnesses. For doing of the STS test, where the number of repetitions during 30 seconds or 1 minute are counted, out puts reproducible results in elderly people (in intra class correlation coefficients $\geq 0.84$ ) and the STS test showed more significant correlations with established tests for exercise capacity and tolerance exercise such as Six-minute walk distance (6MWD) ( $>0.7)$. The STS test and Six-minute walk tests showed very similar correlations with other evaluation measures indicating that they may measure and qualify similar aspects of functional exercise capacity in COPD patients by attention that reached to advance equipment's and standard tests for specialists in clinic. By reports of researchers about $50 \%$ of hospitalized COPD patients have a bodyweight and mass that is less than $90 \%$ of their ideal weight in during of rehabilitation program. In many COPD patients underweight often have a significantly impaired and contrary healthrelated quality of life, decreased exercise capacity and higher mortality compared with non-underweight COPD patients and they have normal body weight. According to recent studies by Puhan, he achieved the cardiopulmonary rehabilitation programmes have been recommended as an integral and complete part of management and treatment for COPD patients. Exercise and physical activity is always regarded as an adjunct and necessary to therapy for most chronic diseases, especially those associated with weight loss for example COPD patients and other respiratory illnesses. In the other hand, recent findings have suggested that exercise and training may create an oxidative stress challenge that COPD patients may not be able to tolerate that and suffer from chronic fatigue in during doing of exercise. These studies and reports showed an increased oxidative stress created in exercise can be response due to increased lipid peroxidation and protein oxidation by free radicals after exercise in patients COPD and rehabilitation program. Increasing in systemic oxidative stress after exercise and physical activity may originate within the contracture muscles and fatigue of COPD patients. Do not enough and inadequate antioxidant activity in body systems and in efficient mitochondrial function handling of oxygen after exercise can be lead to oxidative stress in COPD patients in long of exercise protocol in clinic or home. These results and findings suggest that exercise training may not be advantageous for COPD patients, with underweight in during of cardiopulmonary rehabilitation. In the other hand, there are many discrepancies in studies and researches especially on exercise-induced oxidative stress in COPD patients in rehabilitation period. In studies on COPD these discrepancies may be explained by differences in patient characteristics on physiologic indexes, exercise intensity and time and use of supplemental $\mathrm{O}_{2}$ during exercise by any COPD patients that how much used of supplemental $\mathrm{O}_{2}$ [25-35].

So, with regard to the possible role of hypoxia in the exercise special in moderate and sever COPD-induced inflammatory and oxidative response, it is interesting that oxygen supplementation reduced oxidative stress and effects of free radicals after exercise in these patients. Many research and studies reported that Supplemental $\mathrm{O}_{2}$ seems to reduce the activation of neutrophils and thereby prevents exercise induced production of free radicals in during of exercise but relate to needs of patients to Supplemental $\mathrm{O}_{2}$. It has also been suggested by investigators that supplemental $\mathrm{O}_{2}$ may enhance training intensity and relieve dyspnoea in doing of exercise program clinic in COPD patients. Thus, by attention that upper subject it is important to determine whether exercise training and supplemental $\mathrm{O}_{2}$ improves or worsens and decrease exercise capacity and HRQL in underweight or fixed body weight patients with COPD in moderate and sever level. There are data to suggest that non-invasive ventilation can be used to allow stable COPD patients with Ventilatory limitation to exercise at higher intensities and it has also been used to allow mobilization in patients on an intensive care unit [30-40].

\section{Skeletal muscle dysfunctions in COPD (lower limbs)}

Physical activity and exercise limitations are a cardinal feature of COPD patients which is particularly marked in patients who require to clinical practice in hospital. This limitation directly related to skeletal muscle weakness for example quadriceps weakness is associated with increased mortality and morbidity in COPD patients. COPD patients with low physical activity levels are more likely to be admitted to hospital and health care in there by physician team and exacerbations and stresses themselves lead to a dramatic reduction in physical activity and health status which can be prolonged, reflected in reduced time spent outdoors for participation in physical activity program in hospital and clinic. Activity limitation is also associated with a greater likelihood of relapse after discharge following accident and emergency department attendance. Although Miranda et al. argued that muscle weakness special in muscle major in femoral and leg is multi and importance factorial, disuse is likely to be the major reversible factor with loss of strength most pronounced in the muscles of locomotion and performance that COPD patients used of that for more daily activities. Researchers reported an acute fall in strength has been noted in patients admitted with acute exacerbations of COPD (AECOPD) in hospital and decline in fat free mass in COPD is associated with exacerbation frequency and increase of stress in effect of space and muscle skeletal situation. Cardiopulmonary rehabilitation with exercise approach is a well-established therapeutic strategy for out-patients with COPD in hospital and home, improving exercise capacity and quality of life as well as reducing hospital admissions and health care costs of them by attention that intensity illnesses. COPD patients participated in cardiopulmonary rehabilitation program started within 10 days of discharge following AECOPD has been shown to improve exercise capacity, quality of life and readmission rate in hospital and so improvement of daily activity. Benefit has also been seen in patients undergoing a supervised exercise program in their own homes and clinic by covered of physician- research team. Exercise protocol include a six week program begun straight after discharge, with twice weekly visits, improved shuttle walk distance, quadriceps strength and quality of life compared to usual care with a trend towards fewer exacerbations at three months in clinic for COPD patients. In clinic is also some data looking at in-patient programs for patients with AECOPD after they have recovered sufficiently but before discharge from hospital. In these studies and programs COPD patients were enrolled four to seven days after admission to hospital for cardiopulmonary rehabilitation program. Researchers and investigators found that walking distance almost doubled in the intervention arm in fact that it did not change in the control group when they are comparing with COPD patients. Many benefits of this early rehabilitation program in improvement of exercise capacity; breathlessness and quality of life were large and appeared to be maintained with unsupervised home exercise program suggesting that the benefits from preventing or reversing acute deteriorations of muscle strength are important and can be sustained relatively easily for COPD patients that participated in this program both of clinic and home. It is therefore possible that, as in stable disease in COPD patients, nonintensive ventilation could support rehabilitation program during an acute episode in patients that have muscle weakness, allowing patients 
to exercise who would otherwise be too breathless and so prevent loss of muscle strength and functional capacity in daily activities in these patients. In COPD patients peripheral muscle weakness has been shown to contribute to exercise intolerance and strength. Nevertheless, Serres et al. argued that muscle weakness alone does not explain the decreased peripheral muscle performance seen in patients with COPD but without participation in physical activity program and hospitalization can be main reason for that. Decreased capacity of local muscle endurance and strength in both the upper and the lower limbs has been shown in COPD patients compared to healthy controls in during of rehabilitation program in clinic. In cardiopulmonary rehabilitation program for COPD patients used different training modalities have been evaluated to uncover the most effective way of training patients with COPD. The primary methods of exercise training within pulmonary rehabilitation have traditionally been different types of exercises incorporating a large amount of muscle mass for employment of them in to do this program in clinic [35-45]. However, increased dyspnea and breathlessness during these whole body/large muscle mass exercises cause many COPD patients to stop exercising program before their cardiovascular system or skeletal muscles are maximally stressed and work loaded. According to a study by Andre Nyberg exercise training using a reduced muscle mass is a way of dealing with this issue in during of exercise and daily activities in COPD patients but muscle mass in them will have more strength and high performance than before. This has been found to achieve a higher metabolic rate due to less stress being placed on the respiratory system as ventilation is decreased compared to whole body exercises than muscles performance for example quadriceps muscle and lower limbs because they have task for translation body in COPD patients in long of daily activates [40-50].

\section{Dyspnea and fatigue in COPD}

A COPD illness is a debilitating lung condition that manifests in shortness of breath, activity limitation, increased sputum production, and cough that he cannot control himself in during exercise on him cardiopulmonary system. COPD patients also demonstrate lower quality of life (QoL), more severe dyspnea and more sensitive airways obstruction. Exercise intolerance program and exercise protocols in clinic is the key disabling factor in COPD patients, with decreased exercise capacity, increased leg fatigue and dyspnea among the most frequently reported symptoms. However, with increase dyspnea and breathlessness during exercises because many COPD patients to stopped exercising before their reach to incremental cardiovascular system or skeletal muscles are maximally stressed in during of improvement program (Cardiopulmonary Rehabilitation program with exercise). COPD patients in the community have a moderate to high prevalence of symptoms include of: fatigue, dyspnea, sputum, and low capacity exercise, cough. Recent studies showed that experience of unpleasant symptoms, such as fatigue, contributes to impaired quality of life in COPD patients. Fatigue is one of the most distressing symptoms of COPD patients, and significantly impairs both functional performance and quality of life in these patients. In all of activities in COPD patients must attendance to fatigue because that is biggest problem in them. Specially fatigue in muscle and intolerance exercise by attention to lung capacity. In the other hand fatigue imposes limitations on motivation, concentration, confidence and the ability to engage in everyday activities such as work, household severity, and social recreations, engendering frustration, depression, grief, and a sense of loss of control on him movements. Measurement of fatigue has been plagued by a lack of consensus on its definition and report of patients, and a lack of agreement on its dimensions inform of grades (Borg scale). While fatigue has been found to be related to dyspnea to reason of low supplement $\mathrm{O} 2$, it does not appear to be directly related to measures of pulmonary function and need to other elements [30-36].

\section{Borg Scale for Rating of Perceived Exertion (RPE)}

The "Borg Scale for Rating of Perceived Exertion "is a useful way of checking the intensity of your exercise program. The scale is also helpful when you are trying to manage a limited amount of energy to complete your daily actions. Using the Borg Scale of Perceived Exertion, you can learn to monitor your performance and intensity. This will pace your effort and help you maintain a moderate level of exertion. Exercising or working at moderate levels will help you to increase your exercise endurance and improve your lung function. The Borg Scale helps you recognize when you are exerting at a level that may put you at risk for injury. Learning to use the Borg Scale of Perceived Exertion does not require any special skills or equipment. The scale lets you keep your exercise pace without having to stop to take your pulse rate. While you are exercising, try to estimate how hard you feel the work is. Rate the degree of perceived exertion you feel. Include the total amount of exertion and physical fatigue. Don't concern yourself with any one factor such as leg pain, shortness of breath or how hard the work is. Try to concentrate on your total, inner feeling of exertion. Estimate your exertion as honestly and neutrally as possible. Rate your perception of the exertion using the Borg Scale. Your goal is to keep a rating between 3 and 4 on the scale. You may feel that you cannot coordinate your breathing to reduce shortness of breath. Or you may have aches and pains longer than 20 to 30 minutes after your exercise session. If so you will need to slow your pace down to 1 or 2 on the scale [45-59].

Studies mentioned that modified Borg Scale for Perceived Dyspnea (Shortness of Breath). The "Rating of Perceived Dyspnea (RPD) Scale" is used during exercise or tasks to decide the amount of shortness of breath you are having. You say how hard you are breathing on a scale of 0 to 10 . On the scale, 0 is "no shortness of breath. "A 10 represents "so much shortness of breath that you have to stop the activity" (Table 2).

\section{Main factors disorders in COPD patients}

Cardiopulmonary rehabilitation programs are designed to optimize physical and daily performance and autonomy in COPD patients. Recently, Eduardo et al. in his studies argued that the efficacy of pulmonary rehabilitation programs in improving functional capacity and disease-specific health perception is well documented in COPD patients and can be observation improvement of symptom in during that. If we can be able to optimize exercise and training for all COPD patients while focusing on local muscle endurance, a clinical trial incorporating upper as well as lower extremity muscles is essential in a good exercise program in clinic and home for these patients. At present peripheral muscle dysfunction is one of the most serious systemic effects of COPD; strategies for improving muscle function (strength and endurance) are a priority in scientific research for improvement of fatigue and dyspnea in COPD patients. Nevertheless, improvement in exercise performance and attention on inflammatory biochemical markers (for example: Creatine Kinase, $\mathrm{CK}$ ) and C-reactive protein (CRP) have been observation in COPD patients when they are fatigue effect of exercise. Hypothesis of many researchers and investigators mentioned that lung function is that the therapeutic effects of local exercise and physical activity as vasodilation, improves the collateral circulation, increasing the level of oxygen content in tissues, and increased levels of mitochondrial ATP could minimize muscle fatigue, increasing exercise tolerance in COPD patients. In finally in this section we believe that Limited research has been conducted to examine various factors that influence fatigue as well as some dimensions of fatigue in COPD patients. The following Table 2 shows the factors that 


\begin{tabular}{|c|c|c|c|c|c|c|c|c|c|c|c|}
\hline Borg & 0 & 0.5 & 1 & 2 & 3 & 4 & 5 & 6 & 7 & 9 & 10 \\
\hline $\begin{array}{l}\text { Rating } \\
\text { Perceived } \\
\text { Exertion Scale }\end{array}$ & Nothing at all & $\begin{array}{l}\text { Very, very weak } \\
\text { (just noticeable) }\end{array}$ & $\begin{array}{l}\text { Very } \\
\text { weak }\end{array}$ & $\begin{array}{l}\text { Weak } \\
\text { (light) }\end{array}$ & Moderate & $\begin{array}{l}\text { Somewhat } \\
\text { strong }\end{array}$ & $\begin{array}{l}\text { Strong } \\
\text { (heavy) }\end{array}$ & - & Very Strong - & - & Maximal \\
\hline
\end{tabular}

Table 2: Measurement of fatigue has been plagued by report of patients, and a lack of agreement on its dimensions inform of grades (Borg scale) for "Rating of Perceived Exertion" in during exercise. Note: Stay between 3 and 4 on the scale unless otherwise instructed.

\begin{tabular}{|c|c|c|c|}
\hline No & First factor & Second factor & Third factor \\
\hline \multirow[t]{10}{*}{1} & \multirow[t]{10}{*}{ Pulmonary limitations in breathing } & $\begin{array}{l}\text { Increased work of breathing from increased airways resistance, expiratory } \\
\text { flow limitation }\end{array}$ & \\
\hline & & \multirow[t]{3}{*}{ Impaired lung emptying, dynamic hyperinflation } & Impaired tidal volume response to exercise \\
\hline & & & Increased elastic load to inspiratory muscles \\
\hline & & & $\begin{array}{l}\text { Mechanical disadvantage of respiratory } \\
\text { muscles (altered length-tension relationship) }\end{array}$ \\
\hline & & \multirow[t]{3}{*}{ Other causes of respiratory muscle dysfunction } & Impaired nutrition \\
\hline & & & Electrolyte disturbances \\
\hline & & & Steroid myopathy \\
\hline & & \multirow[t]{3}{*}{ Gas exchange abnormalities } & $\begin{array}{l}\text { Increased dead space and ventilation/ } \\
\text { perfusion mismatch }\end{array}$ \\
\hline & & & Diffusion impairment \\
\hline & & & Hypoxemia \\
\hline \multirow[t]{4}{*}{2} & \multirow{4}{*}{$\begin{array}{l}\text { Cardiovascular limitations and } \\
\text { resistance }\end{array}$} & \multirow[t]{3}{*}{ Increased pulmonary vascular resistance } & Hypoxic pulmonary vasoconstriction \\
\hline & & & Vascular remodeling \\
\hline & & & Loss of capillary surface area \\
\hline & & Right ventricle stroke volume limitation related to hyperinflation & \\
\hline \multirow[t]{3}{*}{3} & \multirow[t]{3}{*}{ Skeletal muscle dysfunctions } & Muscle weakness & \\
\hline & & Muscle atrophy & \\
\hline & & Enzymatic activation abnormality & \\
\hline \multirow[t]{2}{*}{4} & \multirow[t]{2}{*}{ Psychological disorders } & Anxiety & \\
\hline & & Fear & \\
\hline
\end{tabular}

Table 3: Main factors contributing to physiological and psychological disorders in COPD patients.

influence can the physical and mental disorders patients to see. As you can see there are four main physiological and psychological factors in the pathogenesis of these disorders, which include a number of others. These factors can test patients' ability to tolerate exercise and physical activity throughout the day can lead to disorder and ultimately reduce the quality of life in them [60-74].

\section{Exercise and physical activity in COPD}

Studies of researchers have shown that physical activities and exercise in daily life is an important predictor of risk of hospital readmission and mortality in COPD patients. So, the World Health Organization's Global Initiative for Chronic Obstructive Lung Disease (GOLD) report states that increasing physical participation in everyday activities is among the important goals of treatment in COPD patients and can be short time for rehabilitation program of them. Specialists and Investigators in Guidelines and Articles recommend that a minimum of 30 minutes of daily physical activity of moderate to intensity, such as walking, is necessary to maintain fitness, and those not meeting this standard are considered insufficiently active in COPD patients. Nevertheless, time spent in physical activity during daily life is an important issue in the characterization of physical activity patterns in these patients that have COPD symptoms and can be help to improvement of them. In COPD patients exercise and physical activity was defined as 'general physical condition enhancement inform of regular; in COPD patients for example, walking, cycling or swimming, and/or training of (most) large muscle groups' for example Quadriceps muscle and leg. Exercise and Physical activity has an influence on exercise tolerance and strength muscle, Quality of life and low dyspnoea in COPD patients and whether it influences the number of hospitalization days and number of exacerbations, expressed as oral courses of prednisolone in COPD for evaluation in clinic and hospital. On basic of reports of specialists exercise training promotes better tolerance and power to exercise and improvement of the quality of life of COPD patients. Recently, exercise training is recognized as an essential trend in cardiopulmonary rehabilitation, and a program of cardiopulmonary rehabilitation has short- and long-term benefits, as has been demonstrated on COPD patients and so on quality of life in them. Nevertheless, between of investigators there is no consensus regarding the most appropriate training strategy for all of COPD patients; nor is there agreement regarding the appropriate duration, intensity and frequency of the individual training sessions of training for COPD patients. Many researcher in this field recommended that on most frequently used modalities are walking and cycling for COPD (Male and Female).

\section{Exercise protocols}

Exercise protocols are standard indexes and employed for all of respiratory illnesses special COPD patients in process of Rehabilitation of them in a Pulmonary Rehabilitation program. These exercise protocols must be used by a team work include of: Specialist lung function, Respiratory physiotherapy, Pacemaker Cardiac testing, and trainer of exercise physiologist for learning and doing this protocols [69]. We going to this section identified to all of Exercise Protocols Standards for Cardiopulmonary Rehabilitation in COPD patients by attention to scientific references and resources in this field but by attention to that these exercise protocols explained with complete details in Methodology of this study we introduce of them in below Table 3. 


\section{Incremental cardiopulmonary exercise testing in COPD}

For COPD patients and other cardiorespiratory illnesses exercise testing is being increasingly utilized in clinical practice to evaluate a patient's level of intolerance to exercise and daily activates and the possible underlying causes for this in COPD patients. Cardiopulmonary exercise testing (CPET) is based on the principle that systems such as the respiratory or cardiovascular fail and illnesses more easily and quickly while under stress and pressure special in COPD. In clinical programs exercise forces and powers the systems to the limits of their tolerable ranges, and abnormal response patterns may be observed in patients with various diseases for example COPD. On basic of researchers compared with normal subjects, those with pulmonary disease such as COPD, cardiovascular or metabolic diseases have a reduced tolerance to exercise and show clear abnormalities in their physiologic acclimatization to exercise in terms of the principal exercise variables (e.g. ventilation, heart rate, blood pressure, rate respiratory). Exercise intolerance is defined as the inability to successfully complete a physical task that normal subjects would find tolerable and strength in COPD patient when they are doing an exercise program in clinic. Seriously, in many chronic respiratory special in COPD and cardiovascular diseases exercise intolerance cannot be adequately predicted from resting and variable physiological measurements, such as FEV1, pulmonary diffusing capacity for carbon monoxide or ejection fraction and FVC and FEV1/FVC and other environment factor in these patients. Cardiopulmonary exercise testing (CPET) is considered the gold standard for exercise intolerance evaluation in clinic for COPD patients for identify among advance in improvement of illnesses by attention to symptoms and signs [57]. However during the CPET test, patients are subjected to symptom-limited incremental exercise, breath-bybreath monitoring of cardiopulmonary variables [e.g. pulmonary $\mathrm{O}_{2}$ uptake $\left(\mathrm{VO}_{2}\right)$, pulmonary $\mathrm{CO}_{2}$ output $\left(\mathrm{VCO}_{2}\right)$, minute ventilation $(\mathrm{VE})$, heart rate (HR)], assessment of perceptual responses (e.g. dyspnea, leg discomfort) and measurements such as exercise-related arterial $\mathrm{O}_{2}$ de-saturation, dynamic hyperinflation and limb-muscle strength for cardiopulmonary illnesses, respiratory illnesses (e.g. COPD patients) and diabetic syndrome. CPET tests are the 6-minute walking test and the shuttle walking test, which can be utilized to evaluate the level of exercise intolerance with measurement of distance, duration, heart rate, arterial $\mathrm{O}_{2}$ saturation and VE; they give, however, less physiologic information about the determinants of exercise limitation by attention to situation of COPD patients and heart failed.

\section{Cardiopulmonary rehabilitation in COPD: Exercise approach}

Cardiopulmonary Rehabilitation Programs with exercise approach are increasingly used to treat COPD patients of different degree of severity (mild, moderate and sever), bringing them benefits in terms of improved exercise capacity and quality of life independent of the ambulatory or in-hospital setting adopted and prefers of them in hospital. So, clinical practice guidelines have generally become popular strategies to enhance the process of care, even in the field of cardiopulmonary rehabilitation for COPD patients inform exactly and controlled. On basic suggestions of Vasiliki, the administration of respiratory treatments is a necessary component of Cardiopulmonary Rehabilitation Programs with exercise approach especially in hospitalized patients, and therapist-driven exercise protocols became widely adopted for a broad range of respiratory care services for patients special COPD [71]. The use of therapist-driven exercise protocols (Josep Roca) can lessen over-prescription of treatments and can also maintain or lessen costs of providing care, while showing the best agreement with clinical practice guidelines and Article relevance with COPD. Cardiopulmonary rehabilitation programmes with exercise approach have been recommended as an integral part of management for COPD patients in hospital and home inform of integrative program for treatment of them (Table 4).

\section{Muscle strength (Skeletal muscle strength)}

Patients with COPD present systematic consequences that alter muscle function and mass, which are attributed to factors such as systemic inflammation, hypoxia, and atrophy of type I and IIa muscle fibers, reduced fiber capillarization and oxidative enzyme capacity. Chronic obstructive pulmonary disease is now considered to be a multi-organ disease and reduced muscular function is one prominent feature [60]. The finding in lower limb skeletal muscle is reduced oxidative capacity with muscle fiber shift, reduced mitochondrial density, reduced mitochondrial biogenesis and impaired mitochondrial respiration. In another study, patients with chronic respiratory symptoms suffer peripheral muscle strength impairment of the upper or lower body or both, are more fatigued, and demonstrate impaired lung function test results, FFM, PI max, 6MWD and QoL [61]. Fatigue cannot be predicted by clinical parameters. More specifically, a metaanalysis was conducted and showed an increase of $25 \%$ in maximum knee extensor muscle strength after progressive exercise training compared to no intervention or aerobic training that showed an increase of only $10 \%$ in the knee extensor muscle strength. However, according to another study, progressive resistance exercise did not show significant improvements in maximal exercise capacity or respiratory function. Body composition was examined in two trials and showed an increase in total lean mass and a reduction in total fat percentage after 12 weeks of progressive resistance exercise. The lack of correlation of peripheral muscle strength to FEV1 is justified because while the muscle assessment can be used to measure the systemic limitation, the airway obstruction is used to quantify the pulmonary function limitation. It thus appears that the degree of impaired lung function does not express a limited peripheral muscle, although Sava and Bernard observed that quadriceps strength was significantly correlated to FEV1 [73].

\section{Muscle endurance}

At present, few data are available on skeletal muscle endurance and, for the assessment of peripheral muscle performance; isolated muscle strength alone is too restrictive. In a group of 17 COPD patients, Serres et al. showed positive correlations between specific (local) quadriceps endurance and the physical activity (PA) score, degree of airflow obstruction (i.e. forced expiratory volume in one second (FEV1)) and arterial oxygen tension (Pa,O2). Their findings clearly illustrated that impaired skeletal muscle endurance in COPD patients relates to altered lung function and associated physical inactivity. It was impossible for the authors to determine the respective components of bronchial obstruction and deconditioning in altering skeletal muscle performance. Therefore, studies comparing healthy control subjects and COPD patients according to PA are needed to investigate the role of bronchial obstruction in altering skeletal muscle function. Moreover, to the authors knowledge, no reports exist describing the electromyographically changes or the cardiorespiratory responses while performing a local quadriceps exercise [55-65].

\section{Respiratory Muscle Training (RMT)}

Respiratory Muscle Training (RMT) can be defined as a technique that aims to improve function of the respiratory muscles through specific exercises. It consists of a series of exercises, breathing and other, to increase strength and endurance of the respiratory muscles and therefore improve respiration. RMT is normally aimed at people who suffer from asthma, bronchitis, emphysema and COPD. However, 


\begin{tabular}{|c|c|c|c|c|c|}
\hline Protocol & $\begin{array}{c}\text { Modified Bruce Treadmill } \\
\text { Test (MBTT) }\end{array}$ & $\begin{array}{l}\text { Symptom-limited cycle } \\
\text { ergometer incremental } \\
\text { load test (ILT) }\end{array}$ & $\begin{array}{c}\text { Cycle-ergometer constant load } \\
\text { test (CLT) }\end{array}$ & $\begin{array}{c}\text { Six-Minute Walk Test } \\
\text { (6MWT) }\end{array}$ & $\begin{array}{c}\text { Cardiopulmonary exercise } \\
\text { testing (CPET) }\end{array}$ \\
\hline Authors \& date & Bruce RA et al.(1973) & Neder JR et al. (2003) & Neder JR et al. (2003) & $\begin{array}{l}\text { Iwama et al. (2009) (ERS/ } \\
\text { ATS guidelines). }\end{array}$ & $\begin{array}{l}\text { American Thoracic Society } \\
\text { in } 2003\end{array}$ \\
\hline Patients & $\begin{array}{l}\text { Coronary heart diseases, } \\
\text { cardiac patients, lung } \\
\text { function and heart surgery }\end{array}$ & $\begin{array}{l}\text { Patients with disorders of } \\
\text { cardiopulmonary, cardiac, } \\
\text { asthma, COPD }\end{array}$ & $\begin{array}{l}\text { Chronic respiratory patients, } \\
\text { cardiac patients. }\end{array}$ & $\begin{array}{c}\text { Cardiac and respiratory } \\
\text { patients with severe } \\
\text { situation. }\end{array}$ & $\begin{array}{c}\text { Respiratory diseases, } \\
\text { cardiovascular, haemopoietic, } \\
\text { neuropsychological, skeletal } \\
\text { systems and metabolic } \\
\text { syndrome. }\end{array}$ \\
\hline Propose & $\begin{array}{l}\text { Evaluation of } \\
\text { improvement of } \\
\text { pulmonary patients } \\
\text { especially COPD in long } \\
\text { time of rehabilitation } \\
\text { program }\end{array}$ & $\begin{array}{l}\text { Intensity of exercise in } \\
\text { this test is increasing step } \\
\text { by step for evaluation of } \\
\text { VO2max. }\end{array}$ & $\begin{array}{l}\text { Maximum tolerance in } \\
\text { patients. }\end{array}$ & $\begin{array}{c}\text { Maximum clinical practice } \\
\text { in respiratory and cardiac } \\
\text { patients in time and } \\
\text { distance. }\end{array}$ & $\begin{array}{l}\text { Gold standard assessment } \\
\text { (validity and reliability) in } \\
\text { patients with limited level } \\
\text { of exercise and evaluate } \\
\text { improvement of patients } \\
\text { before and after rehabilitation } \\
\text { protocol. }\end{array}$ \\
\hline Measurement & $\begin{array}{c}\text { Starts at } 1.7 \mathrm{mph} \text { at } \\
\text { a grade of } 10 \% \text {, the } \\
\text { modified test has a zero } \\
\text { stage }(1.7 \mathrm{mph} \text { at } 0 \% \\
\text { grade) and a one-half- } \\
\text { stage ( } 1.7 \mathrm{mph} \text { at } 5 \% \\
\text { grade). }\end{array}$ & $\begin{array}{l}\text { Cycle ergometer pedal } \\
\text { at } 60 \text { rpm is used } \\
\text { with standard vocal } \\
\text { encouragements. } \\
\text { (Borg }>7), \text { SpO2 }<80 \% \text {, } \\
\text { reach the maximum HR } \\
\text { and cannot continue, it } \\
\text { automatically stops. } \\
\text { 1-minute warm-up } \\
\text { period at minimal cycle } \\
\text { ergometer load ( } 15 \mathrm{~W} \text { ), } \\
\text { with } 5 \text { - to } 10 \text {-W increases } \\
\text { every } 2 \text { minutes that are } \\
\text { individually selected to } \\
\text { maintain the period of load } \\
\text { increase in the } 8 \text {-to-12 } \\
\text {-minute range. } \\
\text { One-minute active } \\
\text { recovery using minimal } \\
\text { cycle ergometer and } \\
\text { followed by a 6-minute. }\end{array}$ & $\begin{array}{l}\text { In this test patients are } \\
\text { instructed to pedal at } 60 \mathrm{rpm} \\
\text { and given standard vocal } \\
\text { encouragements every } \\
\text { minute. Workload of } 70 \% \text { of } \\
\text { the maximum intensity and } \\
\text { so in this protocol maximum } \\
\text { tolerance time for each sample } \\
\text { will be measured. Maximum } \\
\text { tolerated time and subsequent } \\
\text { analysis of VO2 and HR on- } \\
\text { kinetics. Initial minimal load } \\
\text { of } 15 \mathrm{~W} \text { is used for } 1 \text { minute } \\
\text { during the warm-up and cool- } \\
\text { down phases and } 6 \text {-minute } \\
\text { passive recovery period. }\end{array}$ & $\begin{array}{l}\text { The therapist should pay } \\
\text { attention to patients and } \\
\text { if they have fatigue or } \\
\text { dyspnea, they must rapidly } \\
\text { stop the test and go to } \\
\text { rest on a chair or bed. It is } \\
\text { performed on a } 30 \text {-meter- } \\
\text { long flat hallway twice } \\
\text { daily with a 30-minute } \\
\text { interval between each } \\
\text { session; the largest value } \\
\text { of distance traveled will } \\
\text { be selected for analysis. } \\
\text { The patients will be } \\
\text { instructed and encouraged } \\
\text { to walk as fast as possible } \\
\text { for } 6 \text { minutes, using } \\
\text { standardized phrases } \\
\text { every minute of the self- } \\
\text { paced tests. [Distance } \\
\text { traveled at } 6 \mathrm{MWT/} \\
\text { predicted distance×100]. }\end{array}$ & $\begin{array}{l}\text { Gloeckl R et al. (2013) stated } \\
\text { that the } 2 \text { CPET protocols } \\
\text { most frequently used in } \\
\text { the clinical setting are the } \\
\text { maximal incremental and } \\
\text { the constant work rate tests } \\
\text { by ergo cycling system. } \\
\text { Interpretation of CPET } \\
\text { involves a systematic review } \\
\text { of the indices of the exercise } \\
\text { capacity [peak oxygen uptake } \\
\text { (VO2 peak), max work rate], } \\
\text { cardiovascular response, and } \\
\text { Ventilatory response and gas } \\
\text { exchange. }\end{array}$ \\
\hline Other explanations & $\begin{array}{l}\text { Bruce test is one of } \\
\text { best tests mostly used } \\
\text { in healthy persons and } \\
\text { cardiorespiratory patients } \\
\text { in all clinical trials. }\end{array}$ & $\begin{array}{l}\text { The patients will be } \\
\text { monitored by pulse } \\
\text { oximetry throughout the } \\
\text { entire test. HR will be } \\
\text { measured using a heart } \\
\text { rate monitor, and dyspnea } \\
\text { and lower limb fatigue } \\
\text { are assessed using the } \\
\text { CR [Category Ratio]-10 } \\
\text { modified Borg scale. }\end{array}$ & $\begin{array}{l}\text { SpO2, HR, BP, feelings of } \\
\text { dyspnea and lower limb } \\
\text { fatigue at rest and peak } \\
\text { exercise in maximum } \\
\text { tolerance will be recorded. The } \\
\text { electrocardiographic tracing } \\
\text { is monitored throughout the } \\
\text { entire test. }\end{array}$ & $\begin{array}{l}\text { SpO2 during exercise will } \\
\text { be measured lightweight } \\
\text { portable pulse oximeter. } \\
\text { The longest 6MWD of } \\
\text { two tests (per-formed } \\
\text { the same day and } \\
\text { separated by } 20 \text { min) will } \\
\text { be the primary outcome } \\
\text { measure. Dyspnea will be } \\
\text { measured the Borg scale. } \\
\text { (Formula HR max }=220 \\
\text { - age). }\end{array}$ & $\begin{array}{c}\text { The response pattern } \\
\text { in respiratory patients is } \\
\text { exampled by (1) decreased } \\
\text { VO2 peak (2), decreased or } \\
\text { normal AT (3), decreased HR } \\
\text { peak (4), normal or decreased } \\
\text { O2 pulse and (5) increased } \\
\text { in VE / MVV, VE/VCO2 } \\
\text { parameters. }\end{array}$ \\
\hline Type exercise & Training test & Training test & Training test & Assessment test & Assessment test \\
\hline
\end{tabular}

Table 4: Clinical Guidelines for Protocols of Exercise testing, ERS/ATS

many people adopt RMT as part of their sports training as this training is designed to strengthen the muscles used for breathing. Studies have shown that regular RMT can increase a person's endurance during cardiovascular exercise or sports activities such as running and cycling. When a person is breathing normally, they typically use between 10 to 15 percent of his or her total lung capacity. With RMT a person can typically increase the amount of lung capacity used. Deeper breathing uses a bit more energy but also allows more oxygen to enter the bloodstream with each breath while strengthening the breathing muscles. Strengthening inspiratory muscles by performing daily breathing exercises for at least six weeks significantly reduces the amount of oxygen these same breathing muscles require during exercise, resulting in more oxygen being available for other muscles. RMT may consist of inspiratory muscle training (IMT) or expiratory muscle training (EMT) or a combination of both includes:
Diaphragmatic reeducation: Slow nasal inspiration and oral expiration aiming for an increased excursion of the diaphragm, observed through elevation of the abdomen and lateral expansion of the thorax. There were 15 repetitions done in dorsal decubitus with the inferior members flexed and 15 repetitions in right and left lateral decubitus.

Profound inspiration: Profound nasal inspiration until reaching the TLC followed by one oral expiration after a short pause. Fifteen repetitions were made in dorsal decubitus with the inferior members flexed. During inspiration the arms were elevated.

Inspiratory hiccups: Short and successive inspirations without periods of apnea, until reaching TLC, followed by a smooth oral expiration until the level of expiratory repose. There were realized 15 repetitions with the individual seated supporting the thorax laterally with the palms of the hands facing upward, creating a light pressure during expiration. 
Resistive inspiration with linear pressure load: The pressure valve system employed was activated by profound inspiration with a scale from 7 to $41 \mathrm{~cm} \mathrm{H}_{2} \mathrm{O}$ denominated Threshold - Training Respiratory Muscles. The load utilized varied from 30 to $50 \%$ of the value of PI max. Three series of 15 repetitions were done with intervals for rest.

\section{Cardiopulmonary stress in COPD}

Right now studies reported that cardiopulmonary rehabilitation programmes have consistently improved exercise capacity, symptoms and quality of life of COPD patients. Physical exercise is an essential component of cardiopulmonary rehabilitation, and endurance training is commonly used in that for increasing of tolerance and exercise capacity in COPD and other respiratory patients. Perfectly, the endurance type of training applied during cardiopulmonary rehabilitation includes cycling and/or treadmill walking for all of patients e.g. COPD. Programmes including relatively high-intensity endurance training have proven to be effective for improvement of illnesses for COPD patients. In the other hand, walking and cycling, other exercise modalities have been described during cardiopulmonary rehabilitation for COPD patients, e.g. resistance is training, calisthenics, arm cranking and stair climbing, short jumping, agility. In clinical rehabilitation, a combination of several of these exercises is often applied and can be influence on improvement of illnesses in COPD. Although it is known that high intensity training leads to more desirable physiological training effects than low intensity training, the cardiopulmonary stress imposed by different exercises is not yet known for improvement of COPD and may be dangerous for them. However, training intensity is conventionally set at a given fraction of an incremental peak exercise response when COPD patients are doing exercise tests in clinic. But low intensity exercise due to the relatively slow $\mathrm{O} 2$ uptake kinetics of patients with chronic diseases special COPD for reason that they have obstruction in airways', the actual metabolic load during somewhat longer exercise bouts may well be underestimated for patients with COPD and heart failed. In best clinics of the world for COPD patients for improve cardiorespiratory fitness, the guidelines for exercise testing and prescription of the American College of Sports Medicine (ACSM) recommend for healthy individuals to exercise three to five times a week at $40-85 \%$ of the maximum $\mathrm{O}_{2}$ uptake, $50 \% \mathrm{VO}_{2} \mathrm{Max}$ or heart rate reserve for $20 \mathrm{~min}$ continuously or at intervals exercise for COPD patients. Whether these recommendations are achieved by patients with COPD is debated and reported by investigators in field of lung function. But recently it is unknown whether the exercise training regimens applied in the context of cardiopulmonary rehabilitation programmes are sufficient to exercise COPD patients at recommended intensities for healthy individuals by attention to symptoms and signs of them. Nevertheless, the amount of time at which patients train, at given intensities, has not yet been studied and must be review by researchers of exercise physiology and training. So, the present authors and specialists measured the cardiopulmonary stress of the different components of an exercise training programme in the context of cardiopulmonary rehabilitation in patients with moderate-to-severe COPD that suffer from inflammation and sickness in during illnesses and must be protection of them relate to intensity exercise. Finally, COPD patients were also analyzed to determine if they were able to exercise at intensities recommended by the ACSM in clinic and home exercise by attention to tolerance and capacity exercise in tests and clinical practice programs for improvement of COPD patients [64-90].

\section{Discussion}

In this section of research we comparing 10 Articles that we analyzed in result and all of details of them with together on physiological indexes and measurement of improvement COPD patients in treatment protocols by scientists and specialists in the clinics world and hypothesis, assumptions of researchers in around of the world. So we reviewed best exercise methods and exercise protocols that standardized by researchers in field of respiratory illnesses and pulmonary rehabilitation. In research of Plankeel et al. analyzed the effects of an intensive pulmonary rehabilitation program in patient's non-oxygen- dependent COPD. This study show that initial mechanisms in these patients can will be as a predictor in exercise limitations in response to pulmonary rehabilitation program. Also in this research cardiovascular limitation patients had more improvement significantly in VO2max than Ventilatory limitation COPD patients. By attention to initial limitation in exercise in COPD patients we observed that improvement in time walk distance. He also reported regardless performance impaired in COPD patients they must participate in Pulmonary Rehabilitation Program in every situation for reach to best function and without ventilate limitations. Hsia et al. showed that, linear treadmill protocol have more advantages for sever COPD patients in use of that in during of rehabilitation [59]. So, this protocol will be increased incremental work rate in exercise tests with fixed walking speed in long test by attention to special limits of them. Appears to this method can be help to other patients that they have disability and scientists and specialists must study on mild and moderate COPD and other cardiopulmonary illnesses because that is new window in front of researchers for help this patient groups. In Cardiopulmonary Rehabilitation clinic, exercises test are performed with propose of diagnosing exercise tolerance in cardiac and respiratory diseases. Keeping of $\mathrm{O}_{2}$ saturation as an evaluation in daily activities is important for specialists and therapists of respiratory about COPD patients. In cycle ergometer testing, COPD patients had less in elicit $\mathrm{O} 2$ desaturation that might occur in during lung ambulation. He also told that we need to methodology for diagnostic and perform cardiopulmonary exercise testing on linear treadmill protocol or cycle ergometer for COPD patients and other respiratory diseases. Researcher also found a new perspective about concern of intensity exercise on COPD patients with high intensity work rates [64-65]. Therapists respiratory were able to keep COPD patients at high level of intensity exercise by attention to guidelines that from baseline in peak performance for direct patients to best symptoms scores that can be able to response of $\mathrm{O}_{2}$ uptake but we must measurement the metabolic assessment in start and during exercise and in recovery exercise. Also, all of COPD patients (moderateto-sever) with airflow obstruction by attention to exercise tolerance of them in high intensity exercise was improvement exercise capacity after that they finished the training program. Cardiopulmonary stress in during of whole-body exercise was increased than resistance training in COPD patients. In this research applied exercise training program able to using for COPD patients in individual and group study to intensity exercise training that by according to American College of Sports Medicine (ACSM). We would not only focus on heart rate for direct of exercise intensity in COPD patients because they have more other symptoms that can be important for living of them and quality of life. It was also shown that in COPD patients overweight are epidemic and often we can see symptoms that frequency in clinical practice samples. COPD patients are obesity, by attention to having low airflow obstruction, but they have less hyperinflation and had more improved peak $\mathrm{VO}_{2}$ than COPD patients with normal BMI, but they have impairment in walking and other exercise tests. Despite of overweight (excess) but Pulmonary Rehabilitation will be best field and beneficial for improvement of symptoms and signs in clinic. In this research we find that weight decrease strategies with exercise training both of home basic and clinical basic is great interesting between researchers and specialists and can be more beneficial for COPD patients. It was also 
shown that by using maximal incremental treadmill exercise test protocols can be developed and increased tolerance exercise in COPD patients with moderate to very sever [48]. This research reported that treadmill testing have more physiological limitations than cycle ergometer and COPD patients often in treadmill tests have more limiting factors : dyspnea and coughing. Christopher et al. reported that many exercise test protocols that able to developed and performed easy in clinical settings and will using in multinational clinical trials in the world special for COPD patients with mild to very sever. Exercise training can be improved impaired balance of the autonomic nervous system (ANS) in COPD patients in clinical programs. They asked that can be considering exercise rehabilitation as an intervention for improvement of sympathovagal imbalance in COPD patients in clinic? Physical activity is as prevention relatively with reduction of risk factors in respiratory mortality in COPD patients in initially of exercise rehabilitation program in clinic and effectiveness on favorably mortality of them. Researchers of this study asked that more clinical questions remained unanswered about optimal exercise training, intensity and repeats of exercise, duration of exercise and basically exercise rehabilitation program that are important as therapeutic points for COPD patients in progress of treatment in clinic. Physicians and physiotherapists must encourage their COPD patients for participation in exercise programs as everyday physical exercise. Some researchers also mentioned that 6 minute step test (6MST) and 6 minute walking test (6MWT) are employment in clinical practice that recommended as an aerobic physical activity with responsiveness aerobic capacity for COPD patients. In this study shown to be beneficial of aerobic exercises for COPD patients special in situations of moderate or severe. We believe that $6 \mathrm{MWT}$ had more beneficial than 6MST for COPD patients, because in 6MWT former was increasing responsive to exercise protocol that it is evidenced for improvement in performance and reduced dyspnea and fatigue in COPD patients. Maarten reported that concerns about exercise in COPD patients are negatively related to walking tests and go to treatment of them special in COPD patients with mild airflow impairments [90]. Therefore, we must discussion with COPD patients that doing treatment and believe that before start of treatment. These findings COPD patients that concerns about treatment special with exercise training help to physicians to understand weak points and abnormal exercise tests that couldn't explain with individual physiological parameters. For prevention and correct of unrealistic fears in COPD patients and making of program inform of demands COPD patient in progress of treatment but not only improvement of treatment for them So, in case of adherence between COPD patients and that is increasing in beneficial outcomes of treatment special in COPD patients with mild to moderate airflow obstruction. Effects of pulmonary rehabilitation program on underweight COPD patients. In COPD patients with underweight had impairments and damages in exercise capacity, inspiratory muscle strength and tolerance exercise. Physical activity with supplemental $\mathrm{O}_{2}$ maybe result to overweight significantly but limited and improvement in exercise capacity and quality of life in COPD patients. We must using of exercise program in clinic for keep-weight and decrease of that in COPD patients by attention to symptoms and signs that as an especially for them. It was also shown that responses of respiratory, cardiovascular and metabolic in Chester step test (CST) and Modified incremental step test (MIST) in peak exercise was same in both of two tests, but had more differences in incremental in longer and higher number of steps special in during of MIST for COPD patients. However, we saw that none of subjects reached the last stage of CST as a record include a pace of 35 steps for per minute, and that was would only can be achieved in MIST between 13 to 14 minute for every testing for someone COPD patients. We must attendance to limitations that recommended by the
American thoracic Society or American college of chest physicians in these tests special for COPD patients with moderate to very severe [90104].

\section{Conclusion}

We know that many researchers told that incremental exercise tests in during of Rehabilitation and exercise tests result to improvement of ventilation, Heart rate exercise, Respiratory rate, exercise capacity and tolerance exercise in COPD patients and we comparing hypothesis, assumptions of researchers in this field. Investigators believed that Cycle ergometer can be more effect on cardiopulmonary Rehabilitation with low stress and high improvement in physiological factors of COPD patients than treadmill and step tests often have more limiting factors: dyspnea and coughing. Researchers allude to important of linear treadmill protocol have more advantages for sever COPD patients in increasing incremental work rate in exercise tests with fixed walking speed in long test by attention to special limits of them in keeping of $\mathrm{O}_{2}$ saturation as an evaluation in daily activities of COPD patients. Specialist's lung functions believe that walking tests had more beneficial than step tests for COPD patients, because was increasing responsive to exercise protocol that it is evidenced for improvement in performance and reduced dyspnea and fatigue in COPD patients. Therapists alluded to responses in respiratory, cardiovascular and metabolic patients in Modified incremental step test (MIST) incremental test in longer and higher number of steps for COPD patients. Researchers told us in COPD patients with underweight and obesity had damages in exercise capacity, inspiratory muscle strength and tolerance exercise. Physical activity with supplemental $\mathrm{O}_{2}$ maybe result to overweight normal significantly. Investigators in lung function for improvement of $\mathrm{VO}_{2} \max$ in Cardiovascular limitation (CVL) than Ventilate limitation (VL) in COPD patients they must participate in Pulmonary Rehabilitation Program. Respiratory Therapists alluded to cardiopulmonary stress in during of whole-body exercise in COPD patients. Peak performance and result of symptom scores can be able to response of $\mathrm{O}_{2}$ uptake, not only heart rate for evaluation of improvement in COPD patients. Researchers understand exercise training can be improved impaired balance of the autonomic nervous system (ANS) in COPD patients in clinical exercise programs. Physical activity is as prevention of risk factors in respiratory mortality in COPD patients. Concerns about treatment special with exercise training maybe help to physicians to understand weak points and abnormal exercise tests that cannot description with individual physiological parameters.

\section{Acknowledgment}

The research supported by Department of Physiology and Immunology, Faculty of Biology, Barcelona University at course academic 2013 Master Physiology Integrative. Thanks a lot of Dr. Teresa Carbonell (Professor titular and coordinator Master) for help me in this study and I appreciation of my Professors in $\mathrm{PhD}$ program Dr. Luis Lores and Dr. Raffaele Fiorillo directors in Parc Sanitari Sant Joan de Deu for developing of my project and support me in research on pulmonary rehabilitation. I hope this research will be help to COPD patients for better rehabilitation exercises in Clinic and home by attention to their situations. This research will be help to Researcher, Therapists , Specialists for separate between exercise tests in Diagnostic exercise test in pretest and posttest Pulmonary Rehabilitation and during of Pulmonary Rehabilitation in progress of Rehabilitation in Clinic by attention to improvement of Physiologic parameters.

\section{References}

1. Jones PW (2001) Health status measurement in chronic obstructive pulmonary 
Citation: Alibakhshi E, Lores L, Fiorillo R (2015) Physiological Factors Relevant to Exercise Tests in Pulmonary Rehabilitation of COPD Patients. J Sports Med Doping Stud 6: 167. doi:10.4172/2161-0673.1000167

Page 10 of 12

disease. Thorax 56: $880-887$

2. O'Donnell DE, Aaron S, Bourbeau J, Hernandez P, Marciniuk DD, et al. (2007) Canadian Thoracic Society recommendations for management of chronic obstructive pulmonary disease - 2007 update. Can Respir J 14 Suppl B: $5 \mathrm{~B}-32 \mathrm{~B}$

3. Ferrari R, Tanni SE, Caram LM, Corrêa C, Corrêa CR et al. (2013) Threeyear follow-up of Interleukin 6 and C-reactive protein in chronic obstructive pulmonary disease. Respir Res 14: 24.

4. Harris-Eze AO, Sridhar G, Clemens RE, Zintel TA, Gallagher CG, et al. (1995) Low-dose nebulized morphine does not improv,e exercise in interstitial lung disease. Am J Respir Crit Care Med 152: 1940-1945.

5. Young IH, Daviskas E, Keena VA (1989) Effect of low dose nebulised morphine on exercise endurance in patients with chronic lung disease. Thorax 44: 387 390.

6. Masood AR, Reed JW, Thomas SH (1995) Lack of effect of inhaled morphine on exercise-induced breathlessness in chronic obstructive pulmonary disease. Thorax 50: 629-634.

7. Beauford W, Saylor TT, Stansbury DW, Avalos K, Light RW (1993) Effects of nebulized morphine sulfate on the exercise tolerance of the ventilatory limited COPD patient. Chest 104: 175-178.

8. Leung R, Hill P, Burdon J (1996) Effect of inhaled morphine on the development of breathlessness during exercise in patients with chronic lung disease. Thorax 51: $596-600$

9. Jennings AL, Davis AN, Higgins JP, Broadley KE (2001) Opioids for the palliation of breathlessness in terminal illness. Cochrane Database Syst Rev 4: CD002066.

10. Oga T, Nishimura K, Tsukino M, Hajiro T, Ikeda A, et al. (2000) The effects of oxitropium bromide on exercise performance in patients with stable chronic obstructive pulmonary disease. A comparison of three different exercise tests. Am J Respir Crit Care Med 161: 1897-1901.

11. Light RW, Muro JR, Sato RI, Stansbury DW, Fischer CE, et al. (1989) Effects of oral morphine on breathlessness and exercise tolerance in patients with chronic obstructive pulmonary disease. Am Rev Respir Dis 139: 126-133.

12. Bott J, Blumenthal S, Buxton M, Ellum S, Falconer C, et al. (2009) Guidelines for the physiotherapy management of the adult, medical, spontaneously breathing patient. Thorax 2009 64: i1-51.

13. Cabot PJ, Dodd PR, Cramond T, Smith MT (1994) Characterization of nonconventional opioid binding sites in rat and human lung. Eur J Pharmacol 268: 247-255.

14. Hill K, Goldstein RS (2007) Limited functional performance in chronic obstructive pulmonary disease: nature, causes and measurement. COPD 4: 257-261.

15. Tancredi G, Quattrucci S, Scalercio F, De Castro G, Zicari AM, et al. (2004) 3-min step test and treadmill exercise for evaluating exercise-induced asthma. Eur Respir J 23: 569-574.

16. Nyberg A, Lindström B, Wadell K (2012) Assessing the effect of high-repetitive single limb exercises (HRSLE) on exercise capacity and quality of life in patients with chronic obstructive pulmonary disease (COPD): study protocol for randomized controlled trial. Trials 13:114.

17. Moore L, Hogg L, White P. (2012) Acceptability and feasibility of pulmonary rehabilitation for COPD: a community qualitative study. Prim Care Respir J 21: 419-424.

18. Swinburn CR, Wakefield JM, Jones PW (1985) Performance, ventilation, and oxygen consumption in three different types of exercise test in patients with chronic obstructive lung disease. Thorax 40: 581-586.

19. Sykes K (1995) Capacity assessment in the workplace: a new step test. Occup Health (Lond) 47: 20-22.

20. Lau HM, Ng GY, Jones AY, Lee EW, Siu EH, et al. (2005) A randomised controlled trial of the effectiveness of an exercise training program in patients recovering from severe acute respiratory syndrome. Aust J Physiother 51: 213 219

21. Camargo AA, Justino T, de Andrade CH, Malaguti C, Dal Corso S (2011) Chester step test in patients with COPD: reliability and correlation with pulmonary function test results. Respir Care 56: 995-1001.

22. Dal CS, Oliveira AN, Izbicki M, Cianci RG, Malaguti C, et al., (2009) Symptomlimited incremental step test in COPD patients: reproducibility and validity compared to incremental cycle ergometry (abstract). Am J Respir Crit Care Med 179: A2364.

23. Qiaojun Zeng and Shanping Jiang (2012) Update in diagnosis and therapy of coexistent chronic obstructive pulmonary disease and chronic heart failure. $J$ Thorac Dis. 4: $310-315$

24. Butcher SJ, Pikaluk BJ, Chura RL, Walkner MJ, Farthing JP, et al. (2012) Associations between isokinetic muscle strength, high-level functional performance, and physiological parameters in patients with chronic obstructive pulmonary disease.7: $537-542$.

25. Davis JA, Whipp BJ, Lamarra N, Huntsman DJ, Frank MH, et al. (1982) Effect of ramp slope on determination of aerobic parameters from the ramp exercise test. Med Sci Sports Exerc 14: 339-343

26. American Thoracic Society (1999) Skeletal muscle dysfunction in chronic obstructive pulmonary disease. A statement of the American Thoracic Society and European Respiratory Society. Am J Respir Crit Care Med 159: S1-40.

27. Lan CC, Yang MC, Lee CH, Huang YC, Huang CY, et al. (2011) Pulmonary rehabilitation improves exercise capacity and quality of life in underweight patients with chronic obstructive pulmonary disease. Respirology 16: 276-283.

28. Puhan M, Scharplatz M, Troosters T, Walters EH, Steurer J (2009) Pulmonary rehabilitation following exacerbations of chronic obstructive pulmonary disease. Cochrane Database Syst Rev 21: CD005305.

29. Swallow EB, Reyes D, Hopkinson NS, Man WD, Porcher R, et al. (2007) Quadriceps strength predicts mortality in patients with moderate to severe chronic obstructive pulmonary disease. Thorax 62: 115-120.

30. Butcher SJ, Meske JM, and Sheppard MS (2004) Reductions in functiona balance, coordination, and mobility measures among patients with stable chronic obstructive pulmonary disease. J Cardiopulm Rehabil. 24: 274-280.

31. Chaouat A, Weitzenblum E, Kessler R, Charpentier C, Enrhart M, et al. (1999) A randomized trial of nocturnal oxygen therapy in chronic obstructive pulmonary disease patients. Eur Respir J. 14: 1002-1008.

32. Maltais F, LeBlanc $P$, Jobin J, Casaburi $R$ (2000) Peripheral muscle dysfunction in chronic obstructive pulmonary disease. Clin Chest Med 21: 665-677.

33. Roig M, Eng JJ, Maclntyre DL, Road JD, Reid WD (2010) Associations of the Stair Climb Power Test with muscle strength and functional performance in people with chronic obstructive pulmonary disease: a cross-sectional study. Phys Ther 90: 1774-1782.

34. Roig M, Eng JJ, Maclntyre DL, Road JD, Reid WD (2011) Deficits in muscle strength, mass, quality, and mobility in people with chronic obstructive pulmonary disease. J Cardiopulm Rehabil Prev 31: 120-124.

35. Fran Dyer, Lizzie Flude, Farid Bazari, Caroline Jolley, Catherine Englebretsen (2011) Non-invasive ventilation (NIV) as an aid to rehabilitation in acute respiratory disease. BMC Pulm Med. 11: 58

36. Bottaro M, Machado SN, Nogueira W, Scales R, Veloso J (2007) Effect of high versus low-velocity resistance training on muscular fitness and functional performance in older men. Eur J Appl Physiol 99: 257-264.

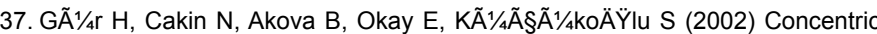
versus combined concentric-eccentric isokinetic training: effects on functional capacity and symptoms in patients with osteoarthrosis of the knee. Arch Phys Med Rehabil 83: 308-316.

38. Curtis BM, O'Keefe JH Jr (2002) Autonomic tone as a cardiovascular risk factor: the dangers of chronic fight or flight. Mayo Clin Proc 77: 45-54

39. Chhabra SK, De S (2005) Cardiovascular autonomic neuropathy in chronic obstructive pulmonary disease. Respir Med 99: 126-133.

40. Lacasse M, Maltais F, Poirier P, Lacasse Y, Marquis K, et al. (2005) Postexercise heart rate recovery and mortality in chronic obstructive pulmonary disease. Respir Med 99: 877-886.

41. Piepoli MF, Davos C, Francis DP, Coats AJ; ExTraMATCH Collaborative (2004) Exercise training meta-analysis of trials in patients with chronic heart failure (ExTraMATCH). BMJ 328: 189

42. Shetler K, Marcus R, Froelicher VF, Vora S, Kalisetti D, et al. (2001) Heart rate recovery: validation and methodologic issues. J Am Coll Cardiol 38: 1980-1987.

43. Ohuchi H, Suzuki H, Yasuda K, Arakaki Y, Echigo S, et al. (2000) Heart rate recovery after exercise and cardiac autonomic nervous activity in children. Pediatr Res 47: 329-335 
Citation: Alibakhshi E, Lores L, Fiorillo R (2015) Physiological Factors Relevant to Exercise Tests in Pulmonary Rehabilitation of COPD Patients. J Sports Med Doping Stud 6: 167. doi:10.4172/2161-0673.1000167

Page 11 of 12

44. Cheng YJ, Lauer MS, Earnest CP, Church TS, Kampert JB, et al. (2003) Heart rate recovery following maximal exercise testing as a predictor of cardiovascular disease and all-cause mortality in men with diabetes. Diabetes Care 26: 2052 2057.

45. O'Donnell DE, Bertley JC, Chau LK, Webb KA (1997) Qualitative aspects of exertional breathlessness in chronic airflow limitation: pathophysiologic mechanisms. Am J Respir Crit Care Med 155: 109-115

46. Killian KJ (2004) Limitation to muscular activity in chronic obstructive pulmonary disease. Eur Respir J 24: 6-7.

47. Jone NL: Clinical Exercise Testing (3rdedn). Philadelphia, WB Saunders Co. 1988.

48. Cooper CB (2001) Exercise in chronic pulmonary disease: limitations and rehabilitation. Med Sci Sports Exerc 33: S643-646.

49. Elpern EH, Stevens D, Kesten S (2000) Variability in performance of timed walk tests in pulmonary rehabilitation programs. Chest 118: 98-105.

50. Mahler DA, Donohue JF, Barbee RA, Goldman MD, Gross NJ, et al. (1999) Efficacy of salmeterol xinafoate in the treatment of COPD. Chest 115: 957-965.

51. O'Donnell DE, Flüge T, Gerken F, Hamilton A, Webb K, et al. (2004) Effects of tiotropium on lung hyperinflation, dyspnoea and exercise tolerance in COPD. Eur Respir J 23: 832-840.

52. Maltais F, Hamilton A, Marciniuk D, Hernandez P, Sciurba FC, et al. (2005) Improvements in symptom-limited exercise performance over $8 \mathrm{~h}$ with oncedaily tiotropium in patients with COPD. Chest 128: 1168-1178.

53. Revill SM, Morgan MD, Singh SJ, Williams J, Hardman AE (1999) The endurance shuttle walk: a new field test for the assessment of endurance capacity in chronic obstructive pulmonary disease. Thorax 54: 213-222.

54. Saey D, Debigare R, LeBlanc P, Mador MJ, Cote CH, et al. (2003) Contractile leg fatigue after cycle exercise: a factor limiting exercise in patients with chronic obstructive pulmonary disease. Am J Respir Crit Care Med 168: 425-430.

55. Pepin V, Saey D, Whittom F, LeBlanc P, Maltais F (2005) Walking versus cycling: sensitivity to bronchodilation in chronic obstructive pulmonary disease. Am J Respir Crit Care Med 172: 1517-1522.

56. Kaminsky LA, Whaley MH (1998) Evaluation of a new standardized ramp protocol: the BSU/Bruce Ramp protocol. J Cardiopulm Rehabil 18: 438-444.

57. Guenette JA, Webb KA, O'Donnell DE (2012) Does dynamic hyperinflation contribute to dyspnoea during exercise in patients with COPD?. Eur Respir J. 40: 322-329.

58. Francesco Sava, Louis Laviolette, Sarah Bernard, Marie-Josée Breton, Jean Bourbeau, et al. (2011) The impact of obesity on walking and cycling performance and response to pulmonary rehabilitation in COPD. 2011, BMC Pulmonary Medicine 10:55.

59. Hsia D, Casaburi R, Pradhan A, Torres E, Porszasz J (2009) Physiological responses to linear treadmill and cycle ergometer exercise in COPD. Eur Respir J 34: 605-615.

60. Brønstad E, Rognmo O, Tjonna AE, Dedichen HH, Kirkeby-Garstad I, et al. (2012) High-intensity knee extensor training restores skeletal muscle function in COPD patients. Eur Respir J 40:1130-1136.

61. Marcellis RG, Lenssen AF, Kleynen S, De Vries J, Drent M (2013) Exercise capacity, muscle strength, and fatigue in sarcoidosis: a follow-up study. Lung 191: 247-256.

62. Casaburi R, Kukafka D, Cooper CB, Witek TJ Jr, Kesten S (2005) Improvement in exercise tolerance with the combination of tiotropium and pulmonary rehabilitation in patients with COPD. Chest 127: 809-817.

63. Buchfuhrer MJ, Hansen JE, Robinson TE, Sue DY, Wasserman K, et al. (1983) Optimizing the exercise protocol for cardiopulmonary assessment. J Appl Physiol Respir Environ Exerc Physiol 55: 1558-1564.

64. Probst VS, Troosters T, Pitta F, Decramer M, et al. (2006). Cardiopulmonary stress during exercise training in patients with COPD. European Respiratory Journal 27:1110-1118.

65. Pitta F, Troosters T, Spruit MA, Probst VS, Decramer M Gosselink R (2005) Characteristics of Physical Activities in Daily Life in Chronic Obstructive Pulmonary Disease. Am J Respir Crit Care Med 171: 972-977.

66. Miranda EF, Leal-Junior EC, Marchetti PH, Dal Corso S. (2013) Effects of light-emitting diodes on muscle fatigue and exercise tolerance in patients with
COPD: study protocol for a randomized controlled trial. Trials 14:134.

67. Roca J, Vargas C, Cano I, Selivanov V, Barreiro E et al. (2014) Chronic Obstructive Pulmonary Disease heterogeneity: challenges for health risk assessment, stratification and management. J Transl Med 28: S3.

68. Plankeel JF, McMullen B, Maclntyre NR (2005) Exercise outcomes after pulmonary rehabilitation depend on the initial mechanism of exercise limitation among non-oxygen-dependent COPD patients. Chest 127: 110-116.

69. Jensen D, Alsuhail A, Viola R, Dudgeon DJ, Webb KA, et al. (2012) Inhaled fentanyl citrate improves exercise endurance during high-intensity constant work rate cycle exercise in chronic obstructive pulmonary disease. J pain symptom manage 43: 706-719.

70. Andrade CH, Cianci RG, Malaguti C, Corso SD (2012) The use of step tests for the assessment of exercise capacity in healthy subjects and in patients with chronic lung disease. J. bras. Pneumol 38: 16-24.

71. Georgiopoulou VV, Dimopoulos S, Sakellariou D, Papazachou O, Gerovasili V et al. (2012) Cardiopulmonary Rehabilitation Enhances Heart Rate Recovery in Patients with COPD. Respiratory care 57: 2095-3103.

72. Beaver WL, Wasserman K, Whipp BJ (1986) a new method for detecting anaerobic threshold by gas exchange. J Appl Physiol (1985) 60: 2020-2027.

73. Francesco Sava, Louis Laviolette, Sarah Bernard, Marie-Josée Breton, Jean Bourbeau et al. (2010) The impact of obesity on walking and cycling performance and response to pulmonary rehabilitation in COPD. Pulmonary Medicine 10: 2-10.

74. Marrara KT, Marino DM, Jamami M, Oliveira Junior AD, Di Lorenzo VA (2012) Responsiveness of the six-minute step test to a physical training program in patients with COPD. J Bras Pneumol. 38: 579-587.

75. Porszasz J, StringerW, Casaburi R (2007) Equipment, measurements and quality control in clinical exercise testing. In: Ward SA, Palange $P$, Clinical Exercise Testing. Eur Respir Mon 40: 108-128.

76. Wasserman K, Hansen JE, Sue DY, et al. (2005) Principles of Exercise Testing and Interpretation: Including Pathophysiology and Clinical Applications. Lippincott Williams and Wilkins, Philadelphia.

77. Porszasz J, Casaburi R, Somfay A, Woodhouse LJ, Whipp BJ (2003) A treadmill ramp protocol using simultaneous changes in speed and grade. Med Sci Sports Exerc 35: 1596-1603.

78. Cockcroft A, Beaumont A, Adams L, Guz A (1985) Arterial oxygen desaturation during treadmill and bicycle exercise in patients with chronic obstructive airways disease. Clin Sci (Lond) 68: 327-332.

79. Poulain M, Durand F, Palomba B, Ceugniet F, Desplan J, et al. (2003) 6-minute walk testing is more sensitive than maximal incremental cycle testing for detecting oxygen desaturation in patients with COPD. Chest 123: 1401-1407.

80. Bruce RA, Kusumi F, Hosmer D (1973) Maximal oxygen intake and nomographic assessment of functional aerobic impairment in cardiovascular disease. Am Heart J 85: 546-562.

81. Iwama AM, Andrade GN, Shima P, Tanni SE, Godoy I et. al (2009) The sixminute walk test and body weight-walk distance product in healthy Brazilian subjects. Braz J Med Biol Res 42: 1080-1085.

82. Troosters T, Casaburi R, Gosselink R, Decramer M (2005) Pulmonary rehabilitation in chronic obstructive pulmonary disease. Am J Respir Crit Care Med 172: 19-38.

83. Troosters T, Gosselink R, Decramer M (2000) Short- and long-term effects of outpatient rehabilitation in patients with chronic obstructive pulmonary disease: a randomized trial. Am J Med 109: 207-212.

84. Spruit MA, Gosselink R, Troosters T, De Paepe K, Decramer M (2002) Resistance versus endurance training in patients with COPD and peripheral muscle weakness. Eur Respir J 19: 1072-1078.

85. Neder JA, Jones PW, Nery LE, Whipp BJ. (2000) Determinants of the exercise endurance capacity in patients with chronic obstructive pulmonary disease. The power-duration relationship. Am J Respir Crit Care Med. 162: 497-504.

86. Puente-Maestu L, Sanz ML, Sanz P, Nunez A, Gonzalez F et al., (2001) Reproducibility of the parameters of the on transient cardiopulmonary responses during moderate exercise in patients with chronic obstructive pulmonary disease. Eur J Appl Physiol 2001; 85: 434-441.

87. Garber CE, Blissmer B, Deschenes MR, Franklin BA, Lamonte MJ et al., (2011) American College of Sports Medicine Position Stand. The recommended 
Citation: Alibakhshi E, Lores L, Fiorillo R (2015) Physiological Factors Relevant to Exercise Tests in Pulmonary Rehabilitation of COPD Patients. J Sports Med Doping Stud 6: 167. doi:10.4172/2161-0673.1000167

Page 12 of 12

quantity and quality of exercise for developing and maintaining cardiorespiratory and muscular fitness, and flexibility in healthy adults: guidance for prescribing exercise. Med Sci Sports Exerc 43: 1334-1359.

88. Ngaage DL, Hasney K, Cowen ME (2004) The functional impact of an individualized, graded, outpatient pulmonary rehabilitation in end-stage chronic obstructive pulmonary disease. Heart Lung 33: 381-389.

89. Ergün P, Kaymaz D, Günay E, Erdogan Y, Turay UY, et al. (2011) Comprehensive Outpatient pulmonary rehabilitation: Treatment outcomes in early and late stages of chronic obstructive pulmonary disease. Ann Thorac Med 6:70-76.

90. Maarten J. Fischer, Margreet Scharloo, et. Al (2012) Concerns About Exercise Are Related to Walk Test Results in Pulmonary Rehabilitation for Patients with COPD. Int. J. Behav. Med. 19: 39-47.

91. Ries AL, Bauldoff GS, Carlin BW, Casaburi R, Emery CF, et al. (2007) Pulmonary Rehabilitation: Joint ACCP/AACVPR Evidence-Based Clinical Practice Guidelines. Chest 131: 4S-42S.

92. Nici L, Donner C, Wouters E, Zuwallack R, Ambrosino N, et al. (2006) American Thoracic Society/European Respiratory Society statement on pulmonary rehabilitation. Am J Respir Crit Care Med 173: 1390-1413.

93. Takigawa N, Tada A, Soda R, Takahashi S, Kawata N, et al. (2007) Comprehensive pulmonary rehabilitation according to severity of COPD. Respir Med 101: 326-332.

94. Dal Corso S, Duarte SR, Neder JA, Malaguti C, de Fuccio MB, et al. (2007) A step test to assess exercise-related oxygen desaturation in interstitial lung disease. Eur Respir J 29: 330-336.

95. Andrade $\mathrm{CH}$, Cianci RG, Malaguti C, Corso SD (2012) The use of step tests for the assessment of exercise capacity in healthy subjects and in patients with chronic lung disease. J Bras Pneumol 38: 116-124.

96. Miranda EF, Malaguti C, Corso SD (2011) Peripheral muscle dysfunction in COPD: lower limbs versus upper limbs. J Bras Pneumol 37: 380-388.

97. Bourjeily G, Rochester CL (2000) Exercise training in chronic obstructive pulmonary disease. Clin Chest Med 21: 763-781.

98. Global Initiative for Chronic Obstructive Lung Disease (2011) Global strategy for the diagnosis, management, and prevention of chronic obstructive pulmonary disease. Bethesda, Montgomery.

99. Pereira CA, Barreto SP, Simões JG, Pereira FW, Gerstler JG (1992) Valores de referência para espirometria em uma amostra da população brasileira adulta. J Bras Pneumol 18: 10-22.

100. Pires Di Lorenzo VA, Silva AB, Sampaio LM, Jamami M, Oishi J (2003) Efeitos do treinamento físico e muscular respiratório em pacientes com doença pulmonary obstructive crônica (COPD) grave submetidos a BiPAP. Rev Bras Fisioter 7: 69-76.

101. Pulmonary rehabilitation: definition and essential components. In: JE Hodgkin. Pulmonary rehabilitation. Guidelines to success. Butterworths (Canada) Limited, Canada.

102. Neder JR, Nery LE. (2003) Fisiologia Clínica do Exercício. São Paulo, Artes Médicas.

103. Borg GA (1982) Psychophysical bases, of perceived exertion. Med Sci Sports Exerc 14: 377-381.

104. Rainer Gloeckl, Blagoi Marinov, Fabio Pitta (2013) Practica recommendations for exercise training in patients with COPD. Eur Respir Rev 22: $178-186$ 